\title{
MORFOLOGIA DE FRUTOS, SEMENTES E PLÂNTULAS DE Jatropha curcas
}

\author{
Alex Caetano Pimenta ${ }^{1}$, Katia Christina Zuffellato-Ribas ${ }^{2}$, Bruno Galvêas Laviola $^{3}$ \\ ${ }^{1}$ Biólogo, M.Sc., IFMG, Doutorando em Agronomia, UFPR, Curitiba, PR, Brasil - alex.pimenta@svc.ifmt.edu.br \\ ${ }^{2}$ Bióloga, Dr ${ }^{\mathrm{a}}$., UFPR, Depto. de Botânica, Curitiba, PR, Brasil - kazu @ufpr.br \\ ${ }^{3}$ Agrônomo, Dr., Embrapa Agroenergia, Brasília, DF, Brasil - bruno.laviola @embrapa.br \\ Recebido para publicação: 19/02/2013 - Aceito para publicação: 28/10/2013
}

\begin{abstract}
Resumo
Neste trabalho objetivou-se gerar informações referentes à morfologia de frutos, de sementes e de plântulas de Jatropha curcas L. (Euphorbiaceae) que auxiliem na identificação da espécie e na compreensão do seu processo germinativo e início do seu ciclo biológico. Foram determinados o grau de umidade e o peso de mil sementes, sendo utilizados para descrição e ilustração 50 frutos e 50 sementes. Para descrição e ilustração da plântula, foram colocadas para germinar 120 sementes. O grau de umidade das sementes de Jatropha curcas utilizadas nesse trabalho foi de 7,0\% e o peso de mil sementes igual a 663,9 g. Os frutos são secos, simples, deiscentes, esquizocarpáceos, medem em média 2,82 $\pm 0,18 \mathrm{~cm}$ de comprimento e $2,15 \pm 0,12 \mathrm{~cm}$ de diâmetro e contêm sempre três sementes. As

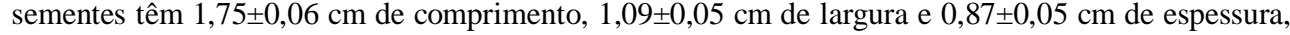
em média, e possuem forma ovoide, coloração preta com estrias amareladas, endosperma e embrião espatulado com cotilédones membranáceos e ovoides arredondados. A germinação se iniciou entre três e quatro dias, encerrando-se aos onze dias após a semeadura no substrato vermiculita, com $90 \%$ de plântulas normais e de desenvolvimento epígeo e fanerocotiledonar.

Palavras-chave: Biocombustível; Euphorbiaceae; pinhão-manso.
\end{abstract}

\begin{abstract}
Morphology of fruits, seeds and seedlings of Jatropha curcas. This research aims to generate information on morphology of the Jatropha curcas L. - Euphorbiaceae fruits, seeds and seedlings, in order to assist the species identification, as well as to understand its germination process and beginning of its biologic cycle. We determined weight and relative humidity of one thousand seeds, while 50 fruits and 50 seeds were used for description and illustration. For seedling description and illustration, we put 120 seeds in germination. The humidity level of Jatropha curcas seeds used in this work was $7,0 \%$ and the weight of one thousand seeds was 663,9 g. Fruits are dry, simple, characterized by dehiscence, schizocarpic, averaging $2,82 \pm 0,18 \mathrm{~cm}$ in length and $2,15 \pm 0,12 \mathrm{~cm}$ in diameter, always containing three seeds. Seeds average dimension is $1,75 \pm 0,06 \mathrm{~cm}$ in length, $1,09 \pm 0,05 \mathrm{~cm}$ in width and $0,87 \pm 0,05 \mathrm{~cm}$ in thickness, they have ovoid shape, black color with yellowish stripes, spoon shaped embryo with membranous rounded ovoid cotyledons. Germination began within three and four days and ended eleven days after sowing in vermiculite substrate, with $90 \%$ of seedlings presenting normal epigeous and fanerocotiledonar development.
\end{abstract}

Keywords: Biofuel; Euphorbiaceae; Jatropha curcas.

\section{INTRODUÇÃO}

O pinhão-manso (Jatropha curcas L. - Euphorbiaceae) é uma planta arbustiva, nativa da América tropical e que apresenta alta plasticidade adaptativa, sendo cultivada em diferentes regiões de clima tropical e subtropical do planeta (OPENSHAW, 2000). Configura-se como alternativa para a produção de óleo destinado para fins energéticos (ARRUDA et al., 2004), pois estima-se produtividade de 6 a 7 ton/ha de sementes/ano após a estabilização da produção. Porém a carência de conhecimentos técnico-científicos sobre a espécie gera uma demanda por pesquisas que viabilizem a implantação do pinhão-manso como cultura agrícola no país (ARRUDA et al., 2004). 
O grande problema para estudos de estrutura, fenologia e comportamento de uma espécie é a sua identificação, pois em determinadas circunstâncias tem-se apenas o fruto, a semente ou a plântula para o reconhecimento das espécies, ou apenas a semente e/ou fruto, como ocorre nos laboratórios de análise de sementes (KUNIYOSHI, 1983). Além disso, na literatura botânica encontram-se dificuldades na conceituação de frutos, em função das grandes variações existentes nas estruturas carpológicas das famílias, dos gêneros e das espécies e da escassez de dados referentes ao assunto (BARROSO et al., 1999). Tais condições se aplicam também às sementes e às plântulas, haja vista a heterogeneidade morfológica devida à plasticidade adaptativa das espécies, em determinados ambientes ou condições, conforme descrito por Rao et al. (2008), os quais constataram variações morfológicas em sementes, na germinação e em plântulas de pinhão-manso de diferentes populações.

O conhecimento prévio da espécie, sobretudo no que se refere às características morfológicas do desenvolvimento da plântula, é fundamental para a interpretação de testes de germinação conduzidos em laboratórios (NUNES et al., 2009; LIMA JR., et al., 2010), pois o acompanhamento do processo germinativo possibilita a interpretação das estruturas finais referentes à normalidade de plântulas (OLIVEIRA; PEREIRA, 1987b). A caracterização dessas estruturas, segundo Oliveira e Pereira (1987b), pode trazer segurança, confiabilidade e eliminar o caráter subjetivo da análise quando minuciosamente descritas e acompanhadas de fotos, ilustrações ou esquemas. A identificação das estruturas reprodutivas e dos estádios de desenvolvimento permite a compreensão de fatores que podem influenciar no estabelecimento, no desenvolvimento inicial e na distribuição geográfica da espécie (COSMO et al., 2010) bem como no entendimento do ciclo biológico da planta (NUNES et al., 2009).

Nas Euphorbiaceae, segundo Barroso et al. (1999), existem características peculiares acerca das estruturas que compõem frutos e sementes, e estas devem ser analisadas convenientemente em grande número de exemplos, para comprovar sua persistência ou variabilidade. Para Oliveira e Pereira (1987b), não se pode afirmar e sequer deduzir que determinada característica é genérica entre os indivíduos da família Euphorbiaceae, dado o grande número de representantes que a compõem e que carecem de estudos sobre os tipos de germinação e suas variações estruturais. Nesse sentido, foram desenvolvidos estudos acerca da germinação de Hura crepitans L., Jatropha molissima (Pohl.) Baillon, Omphalea diandra L. (OLIVEIRA; PEREIRA, 1987b), Aleurites fordii Hemsl., Aleurites moluccana (L.) Wild., Cnidosculus polyanthus I. M. Johnston e Hevea brasiliensis Muell. (OLIVEIRA; PEREIRA, 1987a), além de estudos referentes à morfologia de frutos, sementes e plântulas em Jatropha elliptica Müll. Arg. (AÑES et al., 2005), Jatropha curcas (NUNES et al., 2009) e Sebastiania commersoniana (Baillon) L. B. Smith \& R. J. Downs (COSMO et al., 2010).

Objetivou-se com a presente pesquisa gerar informações referentes à morfologia de frutos, de sementes e de plântulas de pinhão-manso que auxiliem na identificação da espécie e na compreensão do processo germinativo e do início do ciclo biológico da espécie.

\section{MATERIAL E MÉTODOS}

Coleta, seleção e armazenamento: os frutos de pinhão-manso (Jatropha curcas) foram coletados em março de 2011, de dez plantas previamente selecionadas no banco de germoplasma localizado no município de Curvelo, MG, pertencente à Empresa Brasileira de Pesquisa Agropecuária (Embrapa Agroenergia). Posteriormente, os frutos foram armazenados em sacos de polietileno e transportados para o Laboratório de Análise de Sementes, do Departamento de Fitotecnia e Fitossanitarismo, Setor de Ciências Agrárias, Universidade Federal do Paraná, em Curitiba, PR, até a realização dos experimentos, em março/abril de 2012.

Os frutos foram selecionados manualmente, descartando-se aqueles mal formados ou danificados. Posteriormente, eles foram acondicionados em sacos de papel "kraft" e mantidos em câmara seca com UR inferior a $50 \%$ e temperatura inferior a $18^{\circ} \mathrm{C}$, até a realização dos experimentos.

Grau de umidade e peso de mil sementes: o grau de umidade foi determinado pelo método de estufa a $105^{\circ} \mathrm{C}$, e o peso de mil sementes determinado pela média de oito repetições de 100 sementes multiplicadas por dez, respeitando as devidas tolerâncias, conforme estabelecido nas Regras para Análise de Sementes (BRASIL, 2009a). 
Morfologia do fruto: foram separados aleatoriamente 50 frutos para as determinações biométricas (comprimento e diâmetro). Considerou-se como comprimento a região compreendida entre a base (ponto de inserção do pedúnculo) e o ápice do fruto, e o diâmetro foi determinado na porção mediana e transversal do fruto. Para aferir essas medidas, utilizou-se paquímetro digital, e os valores foram expressos em centímetros. Desses frutos foram determinadas as características morfológicas externas e internas do pericarpo, como tipo, forma, coloração, textura, consistência, pilosidade, brilho, deiscência e número de lóculos, de carpelos e de sementes.

Morfologia da semente: utilizaram-se 50 sementes, nas quais foram determinados o comprimento (longitudinal), a largura e a espessura (da região mediana), aferidos com paquímetro digital e expressos em centímetros. Quando necessário, foram realizadas seç̧ões transversais e longitudinais nas sementes para observações, considerando-se as seguintes características: cor, textura, consistência, forma, carúncula, rafe, posição do hilo e da micrópila. No embrião, foram observadas forma, tipo, posição, coloração, eixo hipocótilo-radícula e estrutura de reserva.

Morfologia da plântula: foram colocadas para germinar 60 sementes em substrato papel-toalha na forma de rolo, umedecido com água na proporção de 2,5 vezes seu peso seco e 60 sementes em caixas plásticas $(18 \times 13 \times 12 \mathrm{~cm})$, contendo o substrato vermiculita de granulometria média, umedecido com água em sua capacidade de campo. Os rolos de papel-toalha e as caixas plásticas foram mantidos em germinador tipo Mangelsdorf, com temperatura de $25{ }^{\circ} \mathrm{C}$ e luz constante de $110 \mathrm{Lx}$. Foram observadas as fases compreendidas entre a protrusão da raiz primária e o completo desenvolvimento dos protofilos. Para a caracterização da plântula, foram observados tipo, forma, coloração e pilosidade da raiz e do hipocótilo e consistência, textura, forma, coloração, nervação e tipo de bordo, ápice e base dos protofilos.

As observações do fruto, da semente e da plântula foram realizadas a olho nu ou com emprego de microscópio estereoscópico. Para as características biométricas, efetuou-se o cálculo dos valores mínimo, médio e máximo, com seus respectivos desvio padrão e coeficiente de variação, em planilhas eletrônicas.

As características morfológicas estudadas nesta pesquisa estão baseadas nos trabalhos de Barroso et al. (1999), Vidal e Vidal (2000) e Damião-Filho e Moro (2005).

\section{RESULTADOS E DISCUSSÃO}

\section{Grau de umidade e peso de mil sementes}

O grau de umidade das sementes de pinhão-manso do presente estudo foi de 7,0\% e o peso de mil sementes igual a 663,9 g, assemelhando-se aos resultados obtidos por Höring et al. (2011), que constataram grau de umidade de $8,0 \%$ e peso de mil sementes de 680,0 g. Entretanto, tais valores divergem daqueles obtidos por Silva et al. (2008), que obtiveram grau de umidade de 9,5\% e peso de mil sementes de 469,0 g. Contudo, todos os valores para grau de umidade aqui descritos estão dentro da normalidade, haja vista que sementes com reserva lipídica possuem grau de umidade inferior a 10,0\% (NEVES et al., 2009).

\section{Fruto}

Os frutos do pinhão-manso (Figura 1A-C) são do tipo seco e simples, pedunculados, esquizocarpáceos, tricocas (tricarpelar), sendo as cocas unisseminadas e formadas por valvas constituídas por duas metades de cada um dos carpelos adjacentes, conforme classificação de Barroso et al. (1999). Quando maduros, os frutos são ovais, de superfície rugosa, glabra, marrom, opaca, formada por tecido de consistência cartácea. Possuem em média $2,82 \pm 0,18 \mathrm{~cm}$ de comprimento e 2,15 $\pm 0,12 \mathrm{~cm}$ de diâmetro e contêm sempre três sementes (Tabela 1), exceto em casos de malformação (aborto de óvulos ou de carpelos), e são deiscentes, com abertura longitudinal da sutura dorsal, que se inicia pelo ápice dos carpelos. As cocas externamente possuem as características determinantes à superfície do fruto e internamente são formadas por tecidos amarelos e opacos sobrepostos, sendo que parte é espessa e reticulada, constituída por cordões fibrosos arranjados em forma de rede de malhas e parte é 
membranácea, lisa e rija. O carpóforo é uma coluna central do pericarpo, prolongada a partir do pedúnculo, ao qual permanece preso mesmo após a separação dos carpelos.

Comparando-se os dados obtidos no presente estudo com dados de Jatropha elliptica (AÑES et $a l .$, 2005), percebe-se divergência apenas em relação à superfície do fruto, que é lisa nessa última espécie. Em relação aos frutos de Sebastiania commersoniana (COSMO et al., 2010), as divergências referem-se ao formato e à superfície do fruto, que é subglobosos e liso, respectivamente. As semelhanças entre esses indivíduos se devem, provavelmente, à constância das características botânicas para frutos dentro da família Euphorbiaceae, conforme relata Barroso et al. (1999).

A deiscência explosiva observada nos frutos de pinhão-manso (Figura 1B-C) ocorre naturalmente quando os frutos estão secos, fazendo com que as cocas se fendam longitudinalmente e liberem suas sementes. Esse mesmo sistema de abertura de frutos também foi observado em Jatropha elliptica (AÑES et al., 2005) e, segundo Barroso et al. (1999), trata-se de uma característica complexa, provavelmente originada uma única vez na história evolutiva das angiospermas. Tal mecanismo é um eficiente meio de dispersão de sementes, comum à família Euphorbiaceae, muito embora não seja único, pois existem outras formas de dispersão para propágulos dessa família (WEBSTER, 1994).

A manutenção da integridade do carpóforo mesmo após a separação dos carpelos em frutos de pinhão-manso provavelmente é devida à sua origem, pois, segundo Webster (1994), essa estrutura advém de placentação axilar e permanece como uma columela nos frutos, sendo tipicamente encontrada na família em questão. Entretanto, para Barroso et al. (1999), o carpóforo é uma estrutura que necessita ser estudada mais detalhadamente entre indivíduos da família Euphorbiaceae.

De modo geral, dada a confiabilidade e o alto valor morfológico representado pela constância dos dados (KUNIYOSHI, 1983), é possível afirmar que as características morfológicas do fruto de pinhão-manso descritas e ilustradas neste trabalho são representativas para a espécie.

\section{Semente}

As sementes maduras e secas de pinhão-manso são relativamente uniformes, com médias de $1,75 \pm 0,06 \mathrm{~cm}$ de comprimento, $1,09 \pm 0,05 \mathrm{~cm}$ de largura e $0,87 \pm 0,05 \mathrm{~cm}$ de espessura (Tabela 1$)$. Têm forma ovoide, dorso convexo levemente arredondado e face ventral convexa levemente triangulada (Figura 1D e 1E). O tegumento é seco, rijo, espesso, sendo externamente glabro, liso e de coloração preta, com estrias finas, irregulares e amareladas (Figura 1D), sendo internamente liso e marrom. Possuem carúncula semicircular, levemente cônica e diminuta, de coloração preta, localizada na parte ventral, próxima ao ápice da semente (Figura 1E). A rafe é formada por uma linha reta, longitudinal e ventral, que se estende do hilo à base da semente (Figura 1E). O hilo se constitui em um pequeno ponto de difícil visualização, situado na parte ventral apical da semente, e a micrópila se localiza abaixo da carúncula, sendo fechada por um tecido membranoso (Figura 1G). O tecido de reserva é o endosperma (Figura 1F), de consistência firme e coloração branca, o qual envolve o embrião espatulado, axial e branco (MARTIN, 1946), formado por eixo hipocótilo-radícula cilíndrico e reto (Figura 1F e 1G). Os cotilédones, de acordo com a classificação proposta por Damião-Filho e Môro (2005), são membranáceos, lisos, ovais arredondados e apresentam nervuras (Figura 1F-G).

Os valores observados para dimensões de sementes são muito similares aos valores médios de $1,81 \mathrm{~cm}$ para comprimento, $1,08 \mathrm{~cm}$ para largura e $0,86 \mathrm{~cm}$ para espessura, obtidos para a mesma espécie por Santo et al. (2012). Assemelham-se também aos valores de 1,62 cm para comprimento e de 1,07 cm para largura relatados por Nunes et al. (2009) para sementes de pinhão-manso. As demais características botânicas para sementes descritas neste trabalho foram similarmente descritas por Nunes et al. (2009) em sementes de pinhão-manso e são comumente evidenciadas em outras espécies de Jatropha e para outros gêneros da família Euphorbiaceae.

O endosperma, farto e carnoso, constitui-se em um tecido de reserva oleaginoso, comum à família Euphorbiaceae (WEBSTER, 1994; BARROSO et al., 1999), sendo em pinhão-manso a principal estrutura de reserva das sementes, pois sua massa seca supera a do embrião proporcionalmente em 21:1 (LOPES et al., 2013). Outra importante estrutura encontrada nas sementes de pinhão-manso é a carúncula, dada sua capacidade de atrair formigas dispersoras de sementes (WEBSTER, 1994). Contudo, para algumas espécies do gênero Jatropha, a dispersão primária é realizada por autocoria balística, conforme relatam Neve et al. (2010). 
Tabela 1. Comprimento e diâmetro de frutos, número de sementes por fruto e comprimento, largura e espessura de sementes de Jatropha curcas.

Tabel 1. Length and diameter of fruits, number of seeds per fruit and seeds length, width and thickness of Jatropha curcas seeds.

\begin{tabular}{lcccccc}
\hline Variável & Mínimo & Média & Máximo & $\begin{array}{c}\text { Desvio } \\
\text { padrão }\end{array}$ & $\begin{array}{c}\text { Coeficiente de } \\
\text { variação }(\%)\end{array}$ & $\begin{array}{c}\text { Teste de } \\
\text { Bartlett }\left(\chi^{2}\right)\end{array}$ \\
\hline & & \multicolumn{5}{c}{ Frutos } \\
\hline Comprimento $(\mathrm{cm})$ & 2,39 & 2,82 & 3,18 & 0,18 & 6,3 & $0,2268^{\text {ns }}$ \\
Diâmetro $(\mathrm{cm})$ & 1,86 & 2,15 & 2,47 & 0,12 & 5,5 & $2,2540^{\text {ns }}$ \\
Número de sementes & 3,0 & 3,0 & 3,0 & 0,0 & 0,0 & - \\
\hline & \multicolumn{7}{c}{ Sementes } & & & \\
\hline Comprimento $(\mathrm{cm})$ & 1,62 & 1,75 & 1,87 & 0,06 & 3,3 & $0,7492^{\text {ns }}$ \\
Largura $(\mathrm{cm})$ & 0,92 & 1,09 & 1,29 & 0,05 & 4,5 & $10,8864^{\mathrm{ns}}$ \\
Espessura $(\mathrm{cm})$ & 0,71 & 0,87 & 1,02 & 0,05 & 5,4 & $7,5911^{\text {ns }}$ \\
\hline
\end{tabular}
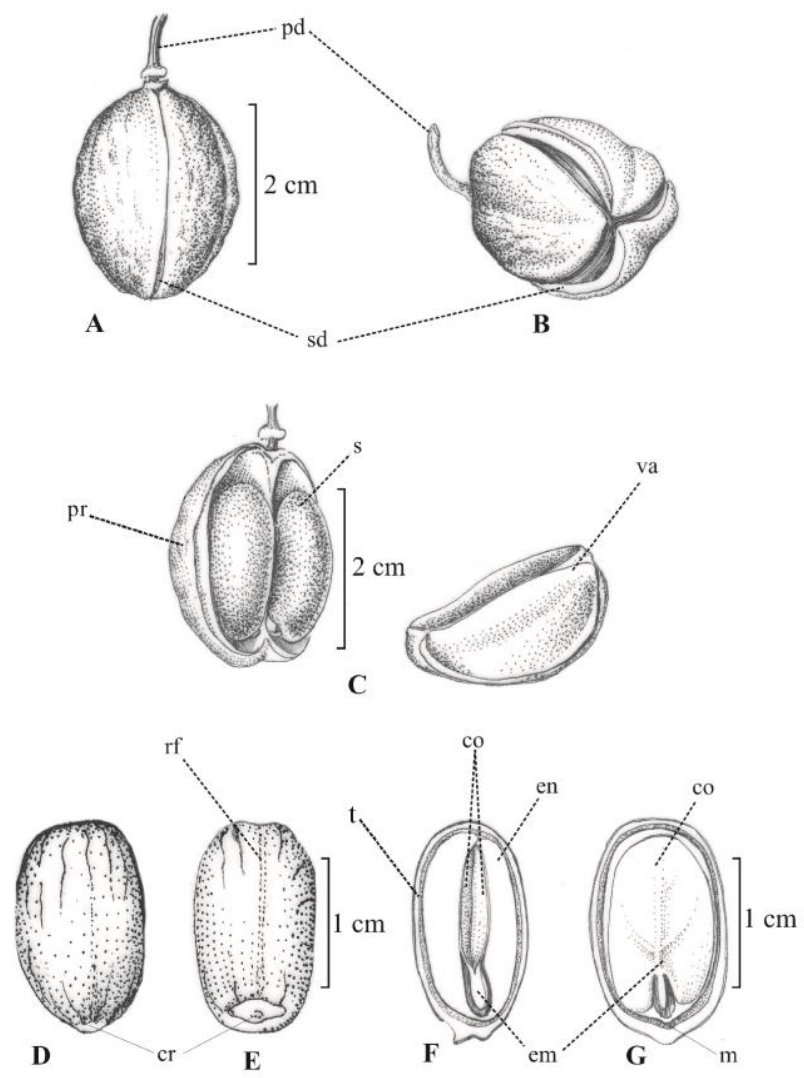

Figura 1. Jatropha curcas A: fruto em vista lateral; B: ápice do fruto; C: lóculos, sementes e valva; D: semente em vista dorsal; E: semente em vista ventral; F: semente em corte perpendicular à face ventral; G: semente em corte paralelo à face ventral. pd: pedúnculo; sd: sutura dorsal; pr: pericarpo; s: semente; va: valva; rf: rafe; cr: carúncula; t: tegumento; co: cotilédones; em: endosperma; em: embrião; m: micrópila.

Figure 1. Jatropha curcas A: fruit side view; B: top of fruit; C: loculus, seed and valve; D: seed dorsal view; E: seed ventral view; F: seed section perpendicular to ventral face; G: seed section parallel to ventral face. pd: peduncle; sd: dorsal suture; ex: exocarp; end: endocarp; s: seed; va: valve; rf: raphe; cr: caruncles; t: head; tg: tegmen; co: cotyledons; en: endosperm; em: embryo; m: microphile. 


\section{Plântula}

A germinação de sementes de pinhão-manso teve início entre três e quatro dias após a semeadura, pela protrusão da raiz primária (Figura 2A), que rompe o tegumento próximo da região do hilo, e findou com $90 \%$ de plântulas normais ao final do teste. De quatro a cinco dias após a semeadura, o tegumento encontra-se aberto, expondo o endosperma. Nesse estádio, são observadas normalmente cinco raízes, que crescem da região do coleto (Figura 2B), sendo a raiz principal central, reta e pivotante, e as demais periféricas, porém todas são semelhantes, com forma cilíndrica e coloração branca. A formação de uma raiz primária e de outras raízes que surgem do coleto também foi observada por Oliveira e Pereira (1987a) em Aleurites fordii e Cnidosculus polyanthus e por Oliveira e Pereira (1987b) em Jatropha molissima e Omphalea diandra. Segundo esses autores, a raiz primária tem origem na radícula do embrião, e as demais, originadas a partir do colo, devem ser classificadas como raízes adventícias. Essa mesma classificação foi adotada por Añes et al. (2005) ao observarem caracteres semelhantes em Jatropha elliptica.

As ilustrações da figura 2 e as respectivas descrições foram baseadas nas plântulas que cresceram no substrato vermiculita, devido às diferenças morfológicas entre as plântulas cultivadas nos diferentes substratos, decorrentes da velocidade do desenvolvimento, que se manifestaram a partir do sexto dia após o início do teste. Para aquelas semeadas no substrato papel-toalha, o endosperma está contido no tegumento que apresenta rachaduras, enquanto que naquelas semeadas no substrato vermiculita, o endosperma está livre do tegumento e expandido, formando um tecido fino, hialino e gelatinoso, que recobre os protofilos (Figura 2C). Nesse estádio, o hipocótilo é carnoso, cilíndrico, glabro, liso e curvo, sendo possível observar o coleto bem definido, pela diferença de espessura entre o sistema radicular e o hipocótilo.

No sétimo dia após o início do teste, os protofilos estavam livres do resíduo do endosperma, expandidos em posição oposta, e eram verdes, sendo possível classificá-los como paracotilédones, baseando-se na sua forma e coloração, pois, segundo Vogel (1980), a adoção do termo paracotilédone se dá quando os protofilos são homólogos às primeiras folhas verdadeiras. Segundo Brasil (2009b), os cotilédones são folhas embrionárias e podem ser classificados como órgãos de reserva, de função haustorial, e como órgãos fotossintetizantes, sendo esse último comum em plantas fanerocotiledonares, quando então são denominados de paracotilédones. Nesse estádio, também se observou que o hipocótilo assumiu forma retilínea e a raiz axial tinha cerca de quatro centímetros de comprimento, sendo menor em relação às raízes periféricas.

Desse modo, devido à exposição dos cotilédones em relação ao endosperma e ao tegumento e à sua elevação acima do substrato, provocada pelo alongamento do hipocótilo, é possível classificar o desenvolvimento das plântulas de pinhão-manso, segundo Brasil (2009a) e Souza (2009), como epígeo e fanerocotiledonar. Esse tipo de germinação é comum para espécies do gênero Jatropha, como constatado por Oliveira e Pereira (1987b) em Jatropha molissima e por Añez et al. (2005) em Jatropha elliptica.

Aos onze dias após o início do teste de germinação, a plântula estava formada, podendo ser classificada como plântula normal (Figura 2D), conforme critérios de Brasil (2009a). A plúmula, pouco desenvolvida, localiza-se entre os paracotilédones, que estão completamente expandidos, são verdes, peciolados, ovados, de margem lisa, ápice e base obtusos e com nervação peninérvea, concordando com os resultados obtidos por Nunes et al. (2009) para a mesma espécie. As raízes são brancas, cônicas, pilosas e espessas próximas ao coleto, afilando-se à medida que se aproximam da coifa, e o hipocótilo é cilíndrico, glabro, liso, esverdeado e levemente espesso abaixo da região mediana. Segundo Brasil (2009a), hipocótilo grosso é característico de plântulas anormais, entretanto essa característica foi observada em várias espécies da família Euphorbiaceae, como em Hura crepitans, Jathopha molissima e Omphalea diandra (OLIVEIRA; PEREIRA, 1987b) e em Jatropha elliptica (AÑES et al., 2005), sendo que esses últimos constataram a formação de plantas normais a partir dessas plântulas de hipocótilo espesso. 


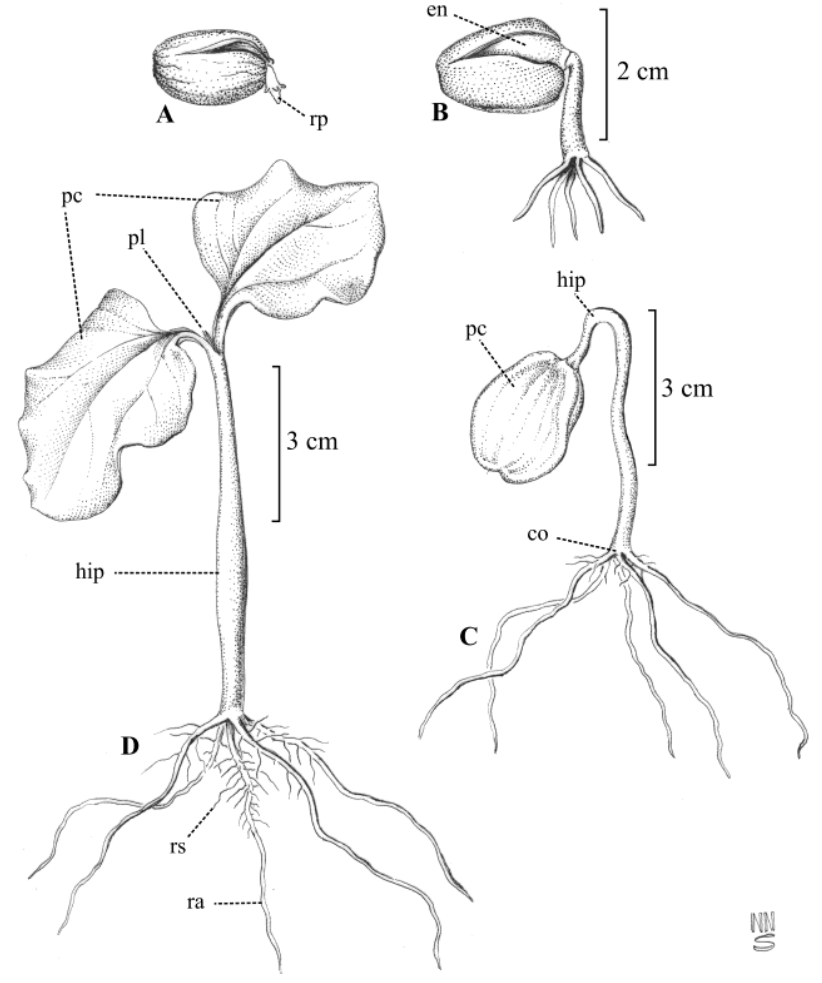

Figura 2. Plântula de Jatropha curcas. A: protrusão da raiz primária; B: abertura do tegumento de 4 a 5 dias após a semeadura; C: plântula com 6 dias; D: plântula com 11 dias. rp: raiz primária; em: endosperma; pc: paracotilédones; hip: hipocótilo; co: coleto; pl: plúmula; rs: raiz secundária; ra: raiz axial.

Figure 2. Jatropha curcas seedling. A: primary root protrusion; B: tegument opening from 4 to 5 days after sowing; C: 6 days old seedling; D: 11 days old seedling. rp: primary root; en: endosperm; pc: paracotyledons; hip: hypocotyl; co: collar; pl: plumule; r: secondary root; ra: axial root.

\section{CONCLUSÕES}

- As características referentes à morfologia de frutos, de sementes e de plântulas descritas e ilustradas neste trabalho são homogêneas e confiáveis suficientemente para auxiliar a identificação da espécie e para a compreensão da germinação e do início do ciclo biológico de Jatropha curcas.

\section{REFERÊNCIAS}

AÑES, L. M. M.; COELhO, M. F. B.; ALBUQUERQUE, M. C. F.; DOMBROSKI, J. L. F. Caracterização morfológica dos frutos, das sementes e do desenvolvimento das plântulas de Jatropha elliptica Müll. Arg. (Euphorbiaceae). Revista Brasileira de Sementes, v. 28, n. 3, p. 563 - 568, 2005.

ARRUDA, F. P.; BELTRÃO, N. E. M.; ANDRADE, A. P.; REREIRA, W. E.; SEVERINO, L. S. Cultivo no pinhão-manso (Jatropha curca L.) como alternativa para o semiárido nordestino. Revista Brasileira de Oleaginosas e Fibrosas, v. 8, n. 1, p. 789 - 799, 2004.

BARROSO, G. M.; MORIM, M. P.; PEIXOTO, A. L.; ICHASO, C. L. F. Frutos e sementes: morfologia aplicada à sistemática de dicotiledôneas. Viçosa: UFV, 1999. 443 p. 
BRASIL. Ministério da Agricultura, Pecuária e Abastecimento. Glossário ilustrado de morfologia. Brasília: Mapa/ACS, 2009b. 406 p.

Regras para análise de sementes. Brasília: Mapa/ACS, 2009a. 399 p.

COSMO, N. L.; NOGUEIRA, A. C.; LIMA, J. G.; KUNIYOSHI, Y. S. Morfologia de fruto, semente e plântula de Sebastiania commersoniana. Floresta, v. 40, n. 2, p. 419 - 428, 2010.

DAMIÃO FILHO, C. F.; MÔRO, F. V. Morfologia vegetal. 2. ed. Jaboticabal: FUNEP, 2005. 172 p.

HÖRING, C. F.; MALAVASI, M. M.; MALAVASI, U. C. Armazenamento não controlado na qualidade de sementes de Jatropha curcas L. Semina, v. 32, n. 2, p. 521 - 526, 2011.

KUNIYOSHI, Y. S. Morfologia da semente e da germinação de 25 espécies arbóreas de uma floresta com Araucaria. 1983. 233 f. Dissertação (Mestrado em Ciências) - Curso de Engenharia Florestal, Setor de Ciências Agrárias, Universidade Federal do Paraná, Curitiba, 1983.

LIMA JR., M. J. V.; FIGLIOLIA, M. B.; PINÃ-RODRIGUES, F. C. M.; GENTIL, D. F. O.; SOUZA, M. M.; SILVA, V. S. Análise de pureza. In: LIMA JR., M. J. V. (Ed.). Manual de procedimentos para análise de sementes florestais. Manaus: UFAM, 2010, cap. 3, p. 27 - 38.

LOPES, L. S.; GALLÃO, M. I.; BERTINI, C. H. C. M. Mobilisation of reserves during germination of Jatropha sees. Revista Ciência Agronômica, v. 44, n. 2, p. 371 - 378, 2013.

MARTIN, A. C. The comparative internal morphology of seeds. American Midland Naturalist, v. 36, n. 3, $513-660,1946$.

NEVES, E. L.; FUNCH, L. S.; VIANA, B. F. Comportamento fenológico de três espécies de Jatropha. Revista Brasileira de Botânica, v. 3, n. 1, p. 155 - 166, 2010.

NEVES, J. M. G.; SILVA, H. P.; BRANDÃO JÚNIOR, D. S.; MARTINS, E. R.; NUNES, U. R. Padronização do teste de germinação para sementes de pinhão-manso. Revista Caatinga, v. 22, n. 4, p. 76 - 80, 2009.

NUNES, C. F.; SANTOS, D. N.; PASQUAL, M.; VALENTE, T. C. T. Morfologia externa de frutos, sementes e plântulas de pinhão-manso. Pesquisa Agropecuária Brasileira, v. 44, n. 2, p. 207 - 210, 2009.

OLIVEIRA, E. C.; PEREIRA, T. S. Euphorbiaceae, morfologia da germinação de algumas espécies I. Revista Brasileira de Sementes, v. 9, n. 1, p. 9 - 29, 1987a.

Euphorbiaceae, morfologia da germinação de algumas espécies II. Revista Brasileira de Sementes, v. 9 , n. 1, p. 31 - 51, 1987b.

OPENSHAW, K. A review of Jatropha curcas: an oil plant of unfulfilled. Biomass and Bioenergy, v. 19, p. $1-15,2000$.

RAO, G. R.; KORWAR, G. R.; SHANKER, A. K.; RAMAKRISHNA, Y. S. Genetic associations, variability and diversity in seed characters, growth, reproductive phenology and yield in Jatropha curcas (L.) accessions. Trees, v. 22, p. 697 - 709, 2008.

SANTOS, H. R. B.; RIBEIRO, M. S.; MEDEIROS, D. B.; NOGUEIRA, J. M. C. Morfometria de sementes de pinhão-manso (Jatropha curcas L.). Scientia Plena, v. 8, n. 4, p. 2 - 4, 2012.

SILVA, H. P.; NEVES, J. M. G.; BRANDÃO JÚNIOR, D. S.; COSTA, C. A. Quantidade de água do substrato na germinação e vigor de sementes de pinhão-manso. Caatinga, v. 21, n. 5, p. 178 - 184, 2008.

SOUZA, L. A. Morfologia e anatomia vegetal: células, tecidos, órgãos e plântulas. Ponta Grossa: UEPG, 2009. 259 p.

VIDAL, W. N.; VIDAL, M. R. R. Botânica organografia: quadros sinóticos ilustrados de fanerógamas. 4. ed. Viçosa: UFV, 2000. 124 p.

VOGEL, E. F. Seedlings of dicotyledons: structure, development, types, descriptions of 150 woody Malesian taxa. Wageningen: Centre for Publishing an Documentation, 1980.

WEBSTER, G. L. Classification of the Euphorbiaceae. Annals of the Missouri Botanical Garden, v. 81, n. 1, p. 3 - 32, 1994. 